\title{
Let's Do it First and Talk About it Later: Rethinking Post-Secondary Science Teaching for Aboriginal Learners
}

\author{
Michelle M. Hogue \\ University of Lethbridge
}

\begin{abstract}
As an oral culture, Aboriginal ways of knowing and learning come through practice and practical application first, rather than through theory or text. For Aboriginal students, the Western methodological approach to learning theory first, poses a counterintuitive near insurmountable roadblock, particularly in science. This paper presents the results of two successful pilot course offerings of an introductory chemistry course in a First Nations' Transition Program; a course that engaged Aboriginal students in a creative, hands-on, practical way. The medicine wheel, in the context of the four seasons (spring, summer, autumn, and winter), is used as the frame to teach chemistry concepts from an Aboriginal cultural lens and beginning with hands-on methodology to establish context and develop experience before bridging to Western theory.
\end{abstract}

Keywords: Aboriginal students; learning theory; curriculum; teaching practices 


\section{Let's Do it First and Talk About it Later: Rethinking Post-Secondary Science Teaching for Aboriginal Learners}

The University of Lethbridge is centrally located within the heart of Blackfoot territory next to the largest reserve, the Blood Reserve, in Western Canada. As such, it is a natural destination institution for (local) Aboriginal ${ }^{1}$ students who wish to pursue post-secondary education (PSE). In spite of its location, the Aboriginal enrolment remains very low $(<5 \%)$ and virtually non-existent in the sciences, aligning with national statistics (Friesen \& Krauth, 2012; Statistics Canada, 2005, 2008). Science and mathematics, as traditionally taught from the Western paradigm, have historically been roadblocks for Aboriginal learners. The challenges begin early in elementary school and most often accumulate as they progress to secondary school resulting in high incompletion and attrition rates from the sciences (CCL, 2006a, 2006b, 2009; CMEC, 2009, 2012), preventing Aboriginal learners from entering into science-related degrees at the postsecondary level without, at the very least, substantial upgrading. Of those who do pursue PSE, nearly all choose non-science-related degrees. Consequently, Aboriginal people are critically under-represented in science-related professions such as medicine, science education, scientific research, and technology at all levels (Bastien, 2004; Battiste, 2005; CCL, 2006a, 2006b, 2009; CMEC, 2002, 2006, 2009, 2012; Helin \& Snow, 2010; INAC, 2005; Statistics Canada, 2010). As well, without science-related professional degrees, Aboriginal people do not have the opportunity to work within their own community as science professionals to build science-related community capacity and self-efficacy in areas of medicine, education, the environment, and thus, do not have equitable voice and representation in policies, governmental or otherwise, that affect First Nations, Métis, and Inuit (FNMI) peoples.

The use of science and technology is pervasive in all sectors of the economy and there are projected professional shortages in these areas, with current pressure already being felt in rural and remote areas. This projected deficit provides a critical opening for the fastest growing population, the Aboriginal population. However, in order to enable access to these current and future opportunities, success in science and mathematics has to occur much earlier (K-12) and at all levels so that Aboriginal students are not streamed away from such courses, continuing, instead, on science-related academic paths at the PSE level.

The Congress of Aboriginal Peoples (CAP) 2010 report, "Staying in School: Engaging Aboriginal Students," describes the many initiatives and programs across the nation targeted at increasing Aboriginal academic success, particularly in the sciences, which have been met with marginal success. Although there are many social and economic issues contributing to Aboriginal students doing poorly and leaving school before completion (CAP, 2010; CCL, 2006b, 2009; CMEC, 2009, 2012), two significant contributing factors are the lack of relevant curriculum and the presence of appropriate teaching methodologies that attend to Aboriginal ways of knowing and learning (AWKL). This is particularly true in the physical sciences, mathematics, and technology (Aikenhead, 1998, 2001; Cajete, 1994, 1999, 2000; CAP, 2010; Hogue, 2011). Key pioneering educators such as Aikenhead (1996, 1998, 2001, 2006, 2011), Bartlett, Marshall, and Marshall (2012), and Lewthwaite, McMillan, Renaud, Hainnu, \& 
MacDonald (2010) to name a few, have worked extensively at integrating Aboriginal ways of knowing into the Western science curriculum. Their work provides a good foundation to build upon for the changes that need to happen to enable success.

The difference between AWKL and those expected by Western education is often perceived as an inability to do science. In my extensive teaching experience, I see that the issue is not inability in science subjects; FNMI students are proficient once they make their own connections to the curriculum, and those who do, have succeeded very well (Hogue, 2011). The issue I believe is how science is taught in the Western academic system, from the theoretical first to the practical much later, particularly at the PSE level. This process is counterintuitive to the learning by doing first pedagogy of AWKL (Aikenhead, 1996, 1998, 2001, 2006, 2011; Bastien, 2004; Battiste, 2005; Cajete, 1999, 2000; Hogue, 2011, 2013). Rather than knowledge written down and contained in textbooks, knowledge in the Aboriginal paradigm as an oral culture is "transferred" from Elders orally and by demonstration. Knowledge is not taught in a top-down lecture format, and learning is not through rote memorization but through exploration, doing, and application (Aikenhead, 1996, 2001; Bartlett et al., 2012; Cajete, 1999). Further, successful learning achievement is not measured through written examination, but through the ability to apply learning and knowledge in the practical living of life. Historically, this was called survival. Hands-on learning and relevant applicability are critical for FNMI success in all areas of learning, but even more so in the sciences and mathematics.

Leroy Little Bear, former director of Harvard University Native American Program, founder of the Native American Studies Department, and professor emeritus at the University of Lethbridge, suggests there is a misperceived adage that "Indians can't do science" (personal communications, (2006-2012). He asks, "Which science are we talking about?" He explains that Natives have always done science. It just is not perceived as such because the model of comparison is that of Eurocentric-based science. A more accurate statement might be that Aboriginal learners often cannot do science in the way it is taught in the Western academic system, a way that is exclusionary to AWKL (Aikenhead, 1996, 1998, 2001; Cajete, 1999).

Often my Aboriginal students tell me that they, "don't get what they (the authors) are talking about in the textbook; the words make no sense," or they ask, "How does this work in my life?" Although non-Aboriginal students might have the same issues, of critical importance for Aboriginal learners is that the Eurocentric-based science as it is taught has little relevance their own lives. Just as Aboriginal science seemingly does not reside within Western science, so Western science, as it is taught, does not fit well within the Aboriginal life-world (Cajete, 1999; Little Bear, personal communications, 20062012). The way in which it is written and most often taught, as concepts and theories first by textbook and lecture-based teaching, and then, secondly, as application to one's lifeworld, makes it a challenge for Aboriginal learners. Additionally, the compartmentalization of science into individual, disconnected subjects, rather than viewing these subjects as holistically interwoven, as related and interrelated, makes it even more challenging to learn and piece together. Without context, it is like expecting someone to know how to ride bicycle when one does not even know what a bicycle is. Art Stinner (1996), an advocate for context-based learning as a means to engage students 
in interesting ways, says, "to motivate students to acquire content knowledge we set contexts that attract them. However, students often cannot deal with the questions and the problems that context generates unless they already have some content knowledge" (p. 247). He refers to this as the large context problem (LCP), and in order to address this, we have to begin early and carry through all levels of education if we want students to have the content with which to ask those complex questions. For most Aboriginal students, context begins with culture. Although there are many changes taking place in curriculum development, specifically in the social studies curriculum in Alberta (Alberta Education, 2005a, 2005b, 2007) where there is now correct and inclusive, and Aboriginal content, though it is limited, AWKL is still not addressed. If we truly want to bridge cultures and enable the success of Aboriginal students, we need to do more than just "tagon" or "infuse" Aboriginal content; we need to rethink curriculum in ways that address the unique learning pedagogies and styles of Aboriginal students. How we build bridges from AWKL to Eurocentric-based science requires an examination of the process: how we teach and, as importantly, how Aboriginal learners learn.

\section{Creating Bridges}

As a person of Métis heritage, I have grown up between two worlds. I am Western educated with a Métis heritage, and thereby reside in a liminal space between two paradigms. This position, at the very least, has provided me with a context to enable my own learning and to be relatively successful at it. Like many of mixed heritage, growing up, I was always uncomfortable in that space between because it was confusing, but it has become beneficial to me as an educator in that I have an understanding of both ways of knowing and learning, an understanding I am now able to apply to the courses I develop and teach.

My passionate interest in finding ways to enable FNMI student learning success in science began many years ago. I had for the first time in my chemistry class a mature Aboriginal female student who was returning to PSE after being away for many years to pursue her goal to become a doctor. Chemistry, one of the required pre-medicine courses, was a challenge for her: "I can't learn it that way," she told me referring to the textbook; "I have to do it first and then it makes more sense." In working with her I wanted to find ways that enabled her success. She described herself as a visual learner, and as we progressed through the course, I came to understand in working with her that she was a practical hands-on learner. She excelled at the hands-on and could make cultural and learning connections very readily, and would often say when the concept clicked to the theoretical for her, "Oh it's like...." and then give me a relevant example from her own traditional upbringing or her current life context. "It's so much easier when I do it first or at least at the same time as it is being explained, whether that is in science, mathematics, or even other areas," (Esther, 2011 as cited in Hogue, 2011) she said when I interviewed her much later in my doctoral studies. "For me, and I think for most Native students, it is such a big leap to go from the Native way of learning to what is expected in Western school" (Esther, 2011 as cited in Hogue, 2011).

As the Coordinator and a professor within the First Nations’ Transition Program (FNTP), I have been puzzling over how to teach science in ways that work and connect for Aboriginal students, ways that invite and engage them into the science conversation, 
and ways that enable their success so they can continue in the sciences and are afforded the same opportunities at science-related careers as non-Aboriginal peoples. I focus on the following questions: How can we create bridges that enable the success of Aboriginal learners in science? What do we need to change? How do we make those changes in the current curriculum and practice of teaching that can enable that? and How do we make science relevant in ways that attend to AWKL?

One of the greatest challenges in developing culturally relevant curriculum is the juxtaposition between Aboriginal and Western paradigm views. There is no specific word for science, for example, in the Aboriginal paradigm and especially for individual disciplines such as chemistry, physics, biology, and so forth. Rather, science in the Aboriginal paradigm is inclusive; everything is connected and interconnected, related and inter-related, including the animate and the inanimate with a spiritual dimension that does not exist in Western science (Aikenhead, 1996, 1998, 2001, 2006, 2011; Cajete, 1999, 2000, Little Bear, personal communications, 2006-2012). As an oral culture, Aboriginal knowledge is held by designated knowledge-keepers within specific societies, by the Elders in tradition and ceremony. Unlike in the Western paradigm, there is no formal written knowledge (textbooks) or formal collective teaching (lecturing to a classroom of students in rows) from which to learn. The keepers and teachers of traditional knowledge are the Elders and learning is experiential, by observation and hands-on practical doing.

Such ways of learning that are seemingly opposite to Western ways add to the paradigm clash and serve as barriers for many Aboriginal learners (Aikenhead 1998, 2001; Battiste, 2005; CCL, 2006a, 2007) who are expected to leave their cultural ways of knowing and learning at the door of Western education and assimilate into Western education practice (i.e. learn in the Western way). For most this does not work and the failure of the Western education system to attend to AWKL results in low retention and success rates in science and mathematics (CCL, 2006a, 2006b, 2007, 2009; Hogue, 2011; Statistics Canada, 2012). To address this paradigm clash, as curriculum developers and educators, we need to step outside the current curriculum box and think creatively in order to develop curriculum and teaching methodologies that enable Aboriginal science and mathematics academic success within the context of the Western education system.

When I think of chemistry, I think of being in the laboratory, of mixing reagents (the reactants) together to see what happens, all the things that were a draw for me in my early educational years. Like Oliver Sacks (2002) in Uncle Tungsten: Memories of a Chemical Boyhood, as a student it all came together for me in the laboratory, when I experienced the chemistry. The descriptions in the textbook, the reactions, the challenging words that really did not make sense when reading the textbook came together for me in the doing of it, in the practical. The visual and hands-on experience put knowledge into an understandable context for me, albeit in an "ideal laboratory" environment. But the doing was the hook. I always wanted to know more. What would happen if I changed this? or that? How does this work in the "real" world? To me the real world was (and still is) where it really counted. The late educator and curriculum guru, Ted Aoki (1999, 2005) talked often of the juxtaposition between curriculum as planned (or written) and curriculum-as-lived. For many Aboriginal students, this is also the challenge: connecting the science as lived with the science curriculum as taught, particularly over a cultural divide. As an oral culture, Aboriginal teaching and learning 
happens through demonstration and practice first, through trial and error and application; explanation is done through narrative, story, and traditional practices and the teachings of the elders - in other words, by hands-on, practical, and applied, or by Ted Aoki's (2005) philosophy of lived curriculum. The textbook in the Aboriginal paradigm is the real and applied world. Doing and practice come before formal explanation. It makes more sense, then, as educators, to begin with the practical-hands on first (curriculum-as-lived) for Aboriginal learners and then bridge to the curriculum-as-written (the theoretical/textbook), after they have experience and a context as a frame of reference.

Models such as the 5E Teaching Cycle (engage, explore, explain, elaborate, evaluate) first developed in the United States for K-12 curriculum, intended to increase science engagement and retention through hands-on/mind-on inquiry-based learning, have had positive outcomes (Bybee, et al., 2006; Stamp \& O’Brien, 2005). However, this and other such early active-learning models are often replaced by more passive learning through formal textbook and lecture-based teaching, particularly at the secondary and PSE levels (Aikenhead, 2001, 2006; Alberta Education, 2005a, 2005b; Lewthwaite et al., 2010; Toscano, 2013). Many learners find this transition from the early, more practical learning methodologies to the more theoretical ways of learning, very difficult. For Aboriginal students in particular, who are also expected to bridge to a context and way of learning that is counterintuitive and does not fit with their "curriculum-as-lived" (Aoki, 1999) world, this poses a near insurmountable roadblock, and consequently, most begin to disengage and opt out of science. Those who have succeeded found ways to build their own bridges (Hogue, 2011) from AWKL to Western ways of knowing and learning (WWKL).

In my current position as Coordinator of the First Nations' Transition Program, as well as in my research with on-reserve high school students, I have had the opportunity to be immersed in teaching cohorts of only FNMI students in my chemistry course and to witness their struggles in learning science; by science I mean Western science. It became clear to me very early in teaching chemistry to FNMI students that the more hands-onpractical my teaching was, the better the students engaged and learned. One of my students said, "I need to see and do what it is you are talking about. Then I can make the connection, otherwise I have no idea” (FNTP student, personal communication, 2012). Another student said of the textbook, "I have no idea where to begin. There is so much on one page and I don't know what most of these words mean anyway" (FNTP student, personal communication, 2011). Both these statements are reflective of what I saw the students experiencing. It was not, and is not, that they could not "do science," but that they needed to be able to make relevant connections; they needed a starting point, and a context, and a language, and some way of bridging what they already knew to what they needed to do in a practical way, first. If they could touch, feel, and do it, they engaged and stayed engaged. More often I began to use my lecture time to squeeze in more laboratory time and in doing so began seeing not only greater engagement (it was the only time I had perfect attendance), but also greater success. I began to ask the questions: "Does it really matter how we get to the endpoint as long as we do?" and "What would happen if we started with the practical (experimental) first and then moved the theory at the end?" In my Master's thesis, I coined the phrase, endbeginnings (H-duke, 2004); could we use that concept here? Trilling and Fadel (2009) in $21^{\text {st }}$ Century Skills: 
Learning for Life in our Times suggest that, although the revised version of Bloom and Kravohol's 1956 original “Taxonomy of Learning” is better (remember, understand, apply, analyze, evaluate, and only lastly, create), it is still restricted to a way of learning that is not conducive to the learning style of the $21^{\text {st }}$ century learner. A more relevant version for the $21^{\text {st }}$ century learner, they suggest, is one that is interconnected beginning with "creating, applying, remembering, analyzing, understanding, and evaluating" (Trilling \& Fadel, 2009, p. 51). Interestingly, this parallels AWKL.

With this in mind, two years ago, I decided to eliminate the textbook, an expensive book I learned the students were not using anyway, and to redevelop and teach the introductory chemistry course from a practical, hands-on approach entirely in the laboratory. Importantly, I wanted to find bifurcation points, both in learning style and in bridging paradigms, that would enable Aboriginal student success so they could advance to upper-level science courses. As such, I also wanted to develop the course with a context that was culturally relevant to their curriculum-as-lived lives. Although this counters how science, particularly at the PSE level is taught, I hypothesized that if we began in a practical way that attended to AWKL and helped them to build bridges to WWKL, we might see better engagement, success, and retention.

\section{Hands-on First}

Spiral curriculum, first described by Jerome Bruner (1960) in The Process of Education in its iterative revisiting of topics is intended to deepen one's knowledge of a subject by repetition of the topic as it is taught. In this process, topics are revisited to provide familiarity and at the same time progress in increasing levels of difficulty. Students' confidence in the concepts and their knowledge of the subject increases as new learning is related to previous learning. This concept closely parallels the epistemology of the medicine wheel, which is foundational to the Aboriginal paradigm (Hensley, 2010; Rice, 2005; Weniger-Nabigon, 2010). It is often used culturally as a teaching tool to symbolically represent the stages in many teachings: seasons of the year, life cycles, traditional practices, knowledge, health, and spirituality to name just a few. It is always divided into four equal quadrants that are continually cycled through allowing multiple opportunities to engage in the cycle; each time around is one season or cycle and each time around can be another attempt or builds on the previous cycle. The continual revisiting of concepts in this cyclical process allows for unlimited chances or attempts and increasing confidence and depth of understanding in ways analogous to the spiral curriculum of Jerome Bruner. Such a way of learning and coming to know is also akin to some of the more modern philosophies of curriculum development such as the already mentioned 5E model (Bybee, et al., 2006), the $21^{\text {st }}$ Century Learner approach (Trilling \& Fadel, 2009) and the inquiry-based models (Davis \& Sumara, 2006) often used until middle secondary education in the province of Alberta. Like such models that are intended to break down the barriers and boundaries of the traditional view of curriculum as a series of courses each having its own programme and assessment (Harden \& Stamper, 1999), the medicine wheel does so in a culturally relevant way. It uses a representation that students understand (AWKL) and in that way can be used as a creative bridge to Western educational concepts (WWKL). 
Unlike in the Aboriginal ways of teaching, lesson plans seem to be a formal requirement of Western education. Although I feel lesson plans stifle the spontaneity of learning, they do have merit in terms of lesson guidance. In the development of this course, I wanted a cultural frame, one that was understandable and that could be used both in context and in process as a means of bridging AWKL to WWKL to enable better learning and understanding for Aboriginal students. The medicine wheel has both context and process embedded within its symbolism, and thus, provides a good frame for the implementation of science curriculum. Its structure, patternicity, and the cyclical nature in which it is used, in addition to the number four (key to AWKL, for example four seasons, four directions), provides a context and process with which Aboriginal students are familiar. It is the frame used for the curriculum development and implementation of this hands-on introductory chemistry course. Though it might be considered by some as not challenging current orthodoxy, in that it parallels the traditional experimental method of purpose, procedure, results, and conclusion, it offers a culturally relevant frame and process that attends to AWKL and that can further be used to bridge to Western theoretical concepts once the students have the process, and as a consequent result, a context to refer to.

\section{The Working Wheel}

Spring is a time of new beginnings or new ideas; summer is the time of growth or practical doing; autumn is the time of harvest or analysis, and winter is the time of storage or processing of knowledge and bridging to the next cycle. The concept of a twoeyed $^{2}$ seeing approach to teaching science for FNMI students is based on the philosophy of learning to see from one eye with the strengths of Indigenous knowledges and ways of knowing, and from the other eye with the strengths of Western knowledges and ways of knowing. This concept was used in the methodological approach of this course.

The medicine wheel as described was used as the teaching frame for each experiment or activity. Spring was the introduction of the new idea, or the planting of the seed. Each class began with a 5-10 minute introduction of the concept we were learning for that class. In introducing the concept and providing a bridging context, I began from an Aboriginal paradigm first to illustrate that, though the intended concept is viewed with a different lens (and not with scientific terminology), it does exist in some form within the Aboriginal paradigm. For example, the concepts of prediction and hypothesis, terms used in scientific experiments, are a natural part of the Aboriginal paradigm. Although not formally defined, nor seen in the same way as they are in Western science, they have always been used in practical living,

Prediction in the Aboriginal paradigm, as an example, was a practice, a way of life, and was based on previous lived experiences. Aboriginal ancestors would predict the weather based on environmental signs, energies, patterns, movement of the animals et cetera. As hunter-gatherers they used their senses and relied on their experiential knowledge of patterns of behavior and characteristics, and to make predictions of their current observations. These predictions would then be proven or disproven by "living" (i.e. where to set up camp, hunting, gathering et cetera). One might call such "living” the experiment. Did their prediction prove to be right? 
Based on the outcomes of experience and the success or failure of our predictions we can make an informed guess if we see the same pattern occurring or if we change a parameter in the pattern. This is then an educated guess, because it is based on our experience. In Western science this is called a hypothesis. Hypotheses can be tested to prove or disprove them. In western science the testing occurs through experimentation. In the Aboriginal paradigm the testing of the hypothesis is again through the life doing or living. So certainly prediction and hypothesis and even experiments existed and were a natural part of living and of the Aboriginal paradigm. (Hogue, FNTPChem0500 course materials, 2014)

The brief introduction is built on the outcomes from the previous cycle and is used as the foundation to establish the learning goals of the lesson. The students are asked to consider the question-"What do we want to know?" In asking this question, students engage and think about the purpose for themselves, first. This sets the stage and leads into the practical hands-on component represented by the next stage in the medicine wheel, summer.

Summer is the most engaging for the students and is comprised of an experiment or a hands-on activity that enables the students to learn by doing (applied learning). I encourage collaboration because sharing knowledge in order to enable others is essential to AWKL at all levels. In the Western system, the collaborative learning of early education is often replaced by more individual and often competitive learning in later secondary education and certainly by PSE. For Aboriginal students in particular this does not work well. I have found the students learn best and are more successful when they help each other. My place in this is as the facilitator and I work with the students through guided practice (Saskatoon Public Schools, 2004-2008; Dell'Olio, 2007) to ensure the students are doing activities safely and correctly, and learning proper scientific technique. The goal is to learn-by-doing and because a large part of their learning is to experience and practice on their own, I stand back and allow that to take place. Certainly, mistakes happen, but I like to think of mistakes as a place where "learning happens," and often the best learning happens by making mistakes and learning how to fix them.

\section{Figure 1. The Medicine Wheel of Chemistry}

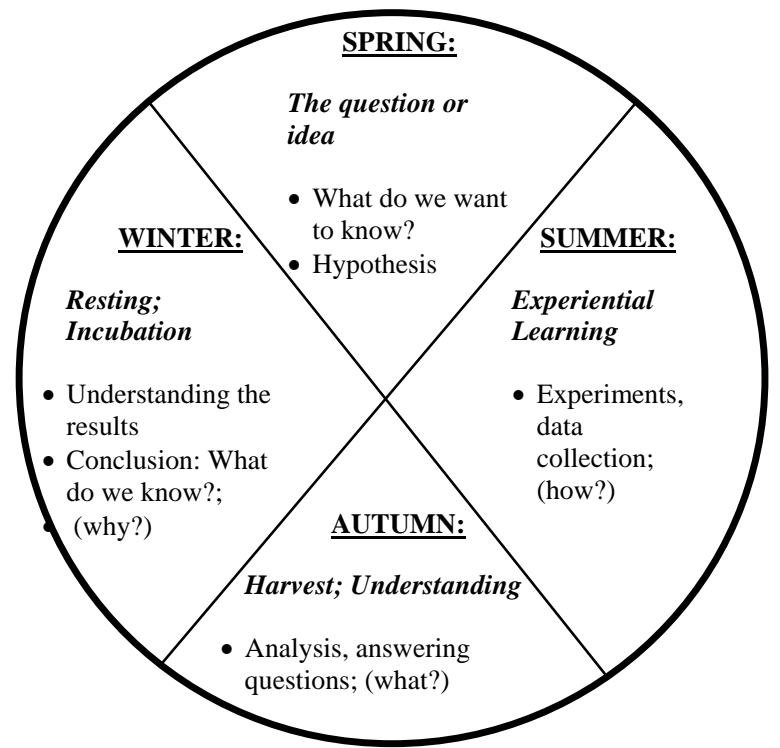

Figure 1. Bridging medicine wheel. The cycle begins with spring and moves clockwise through the seasons to winter 
Once the practical or experimental (the summer growth) is complete, then it is time for the analysis, coming to understand concepts through the results. This equates to the harvest of autumn. Analysis and critical thinking skills are developed in this season. Autumn, is the next stage, and just as the products of any summer are determined by the many factors of summer (heat, rain, temperature etc.), so are outcomes (the harvest) of any experiment or project determined by many factors. At this point, I begin to bring in theory to explain why the outcomes were as they were and build the bridge to Western theory and ways of knowing. Having done the experimental work, students now have a context upon which to build. If I want to talk about reproducibility, for example, I can bridge that to the cycles of the medicine wheel and illustrate its cyclical reproducibility. We can talk about parameters and ask questions about the effects on the outcomes [products] if we make modifications to parameters. I can then talk of how that is related to prediction and hypothesis (as the example above) both in the Aboriginal paradigm and in the scientific paradigm. The students, I have found, understand much quicker and better using this process than if I offer the theory first and expect them to understand it and apply it to an experimental situation. They engage with the material and begin expanding and making connections themselves.

Winter, the last part of the cycle, is the storage and rest time for the future, the time to garner energy. This equates to the conclusion in Western science. It is a time of reflection on outcomes and planning of the next cycle. I have the students reflect critically about what they have learned, and importantly, how it applies to their own lives and how they can think about it in the context of other aspects in their lives, building bridges. "What knowledge is of most worth?" Herbert Spencer (1966) asks, and "How does that move into the next season/cycle? What did you learn? What do you need to change, or keep, to move into the next cycle? What is the next level? What are the bridges?" These are many of the questions students consider as they move to the beginning of the next cycle (or class).

\section{Outcomes}

Although this is still a work in progress, the second implementation of the course using this methodology was an astounding success. Of the nine students registered in the course there was one $\mathrm{A}^{+}$, two $\mathrm{A}^{\prime}$, one $\mathrm{A}-$, one $\mathrm{B}+$, two $\mathrm{B}$ 's, one $\mathrm{C}+$ and one $\mathrm{D}^{+}$. Of note were the number of A's (four out of nine final grades or nearly 50\%) and of great importance is that six of the nine students continued in the sciences: one was accepted into nursing, one into pre-medicine, and the others focused their studies on undergraduate science degrees. In interviews with the students at the end of the course, each said this was the first time they had really understood science and enjoyed it. They wished more courses could be taught this way. One student who had no intention of pursuing science said:

This is the only opportunity I will have in my program to take a chemistry class so I'm taking it as an elective. I'm not great at this, but I still like it and I really wanted to do experiments, so when I learned you were going to teach it all in the lab I just wanted to do it. I'm really glad I took it. (Student Evaluation: FNTP Chem0500, 2013) 
The greatest success story was the $\mathrm{A}^{+}$student. She was a mature student who had been in the FNTP the previous year, had raised a family, had worked fulltime for more than 20 years, and had a dream of becoming a nurse. She had taken chemistry the year before and received a $\mathrm{D}^{+}$, a grade insufficient for entrance into nursing. She repeated the course again and excelled at it. She said the hands-on was critical for her; it was what enabled her to understand because it not only provided context but also, in the practical doing, it connected her to the concepts.

I understood it so much better the second time around because I knew what you were talking about and then I could do it - the first time it was just so much new and foreign information. I needed to see it and do it. The hands-on makes sense. Without it, I'm not sure I could do it. It's why nursing is a draw for me. It's hands-on. (Student Evaluation, FNTPChem0500, 2013)

I do not think that such a way of learning is much different for non-Aboriginal students particularly in today's technologically based society. The difference is in ways of knowing and coming to know. Eurocentric-based science has little context for Aboriginal learners. If one has a context then there is some reference point. Without the context, it does not make any sense, as I have heard from many of my FNMI students who have said such things as, "I have no idea where to begin," and "It makes no sense."

Who says we have to start at the beginning? Who defines what the beginning is? Why not start at the end and go in the other direction? Does it really matter if the result is the desired learning and success at that learning? Beginning with the hands-on practical seems to be a better way to start for Aboriginal learners in this Eurocentric Western system. If we are going to enable the success of the ever-growing population of Aboriginal people in PSE, and particularly, if we want to enable success in the sciences, as educators and curriculum developers, we need to step outside the traditional Western curriculum box and think creatively. This is going to require relevant curriculum, teaching practices, and modes of delivery that attend to AWKL and that enable Aboriginal learners to build bridges between AWKL and WWKL.

Tell me and I'll forget. Show me, and I may not remember. Involve me, and I'll understand.

Native American Saying 


\section{References}

Aikenhead, G. S. (1996). Science education: Border crossing into the subculture of science. Studies in Science Education, 27, 1-51.

Aikenhead, G. S. (1998). Many students cross cultural borders to learn science: Implication for teaching. Australian Science Teachers Journal, 44(4), 9-12.

Aikenhead, G. S. (2001). Students' ease in crossing cultural borders into school science. Science Education, 85, 180-188.

Aikenhead, G. S. (2006). Science education for everyday life: Evidence-based practice. New York, NY: Teachers College Press.

Aikenhead, G. S. (2011). Towards a cultural view on quality science teaching. In D. Corrigan, J. Dillon, \& R. Gunstone (Eds.), The professional knowledge base of science teaching. New York, NY: Springer.

Alberta Education. (2005a). Our words, our ways: Teaching First Nations, Métis and Inuit learners. Edmonton, AB: Aboriginal Services Branch and Learning and Teaching Resources Branch.

Alberta Education. (2005b). Social studies Kindergarten to Grade 12: Program rationale and philosophy. Edmonton, AB.

Alberta Education. (2007). Alberta authorized resource list and annotated bibliography: Social Studies 10-1 and 10-2. Edmonton, AB: Learning and Teaching Resources Branch.

Aoki, T.T. (1999, Summer). Rethinking curriculum and pedagogy: Interview with T. Aoki: Kappa Delta Phi Record, 35(4), 180-181.

Aoki, T. (2005). Layered voices of teaching: The uncannily correct and the elusively true. In W. Pinar \& R. Irwin (Eds.), Curriculum in a new key: The collected works of Ted T. Aoki, (pp. 187-197). Mahwah, NJ: Lawrence Erlbaum.

Bartlett, C., Marshall, A., \& Marshall, M. (2012). Two-eyed seeing and other lessons learned within a co-learning journey of bringing together indigenous and mainstream knowledges and ways of knowing. Journal of Environmental Studies and Sciences, 2, 331-340.

Bastien, B. (2004). Blackfoot ways of knowing. Calgary, AB: University of Calgary Press.

Battiste, M. (2005). State of Aboriginal learning: Background paper for the National Dialogue on Aboriginal Learning. Ottawa, ON: Canadian Council on Learning. Retrieve from http://www.ccl-cca.ca/pdfs/AbLKC/StateOfAboriginalLearning.pdf

Bruner, J. S. (1960). The process of education. Cambridge, MA: Harvard University Press.

Bybee, R., Taylor, J., Gardner, A., Van Scotter, P., Powell, J., Westbrook, A., \& Landes, N. (2006). The BSCS 5E instructional model: Origins and effectiveness. A report prepared for the Office of Science Education National Institutes of Health, BSCS: Colorado 
Springs.

Cajete, G. (1994). Look to the mountain: An ecology of Indigenous education. N.C.: Kivaki Press.

Cajete, G. (1999). Igniting the sparkle: An Indigenous science education model. Skyland, NC: Kivaki Press.Cajete, G. (2000). Native science: Natural laws of interdependence. Santa Fe, NM: Clearlight Publisher.

Canadian Council on Learning (CCL). (2006a). What are the factors that facilitate and impede post-secondary access and participation of Aboriginal students? Ottawa, ON: Government of Canada. Retrieved from http://www.aved.gov.bc.ca/ccl_question_scans/documents/5Aboriginal_Access_and_Participation.pdf

Canadian Council on Learning (CCL). (2006b). What factors facilitate Aboriginal postsecondary success? Ottawa, ON: Government of Canada. Retrieve from http://www.aved.gov.bc.ca/ccl_question_scans/documents/6-Aboriginal_PostSecondary_Success.pdf

Canadian Council on Learning (CCL). (2007). The cultural divide in science education for Aboriginal learners. Ottawa, ON: Government of Canada. Retrieved from http://www.ccl-cca.ca/pdfs/LessonsInLearning/Feb-01-07-The-cultural-divide-inscience.pdf

Canadian Council on Learning (CCL). (2009). The state of Aboriginal learning in Canada: A Holistic approach to measuring success. Ottawa, ON. Retrieved from http://www.ccl-cca.ca/pdfs/StateAboriginalLearning/SALFINALReport_EN.PDF

Congress of Aboriginal Peoples (CAP). (2010). Staying in school: Engaging Aboriginal students. Human Resources and Skills Development Canada (HRSDC). Retrieved from http://www.abo-peoples.org/wp-content/uploads/2012/10/Stay-In-SchoolLR.pdf

Council of Ministers of Education Canada (CMEC). (2002). Best practices in increasing Aboriginal post-secondary enrolment rates. Retrieved from http://www.cmec.ca/postsec/malatest.en.pdf.

Council of Ministers of Education Canada (CMEC). (2006). Best practices in increasing Aboriginal post-secondary enrolment rates.

Council of Ministers of Education Canada (CMEC). (2009). Education indicators in Canada: An international perspective. Retrieved from http://publications.gc.ca/collections/collection_2009/statcan/81-604-X/81-604x2009001-eng.pdf

Council of Ministers of Education Canada (CMEC). (2012). Education indicators in Canada: An international perspective. Retrieved from http://www.statcan.gc.ca/pub/81-604-x/81-604-x2012001-eng.pdf 
Davis, B., \& Sumara, D. (2006). Complexity and education: Inquiries into learning, teaching and research. Mahwah, NJ: Lawrence Erlbaum Associates, Inc.

Dell'Olio, J. M. (2007). Chapter 4: Direct instruction. In J.M. Dell'Olio \& T. Donk (Eds.) Models of teaching: Connecting student learning with students (pp. 71-105). Retrieved from http://www.sagepub.com/upm-data/14255_Chapter4.pdf

Friesen, J., \& Krauth, B. (2012). Key policy issues in Aboriginal education: An evidencebased approach. Toronto, ON: Council of Ministers of Education. Retrieved from www.cmec.ca

Harden, R.M., \& Stamper, N. (1999). What is a spiral curriculum? Medical Teacher, 21(2), 141-143.

H-duke, M. (2004). The chemistry of education: A periodic relationship (Unpublished Masters of Education thesis). University of Lethbridge, Lethbridge, AB.

Helin, C., \& Snow, D. (2010, March). Free to learn: Giving Aboriginal youth control over their post-secondary education. True North in Canadian Public Policy-The MacdonaldLaurierInstitute for Public Policy. Retrieve from http://www.macdonaldlaurier.ca/files/pdf/FreeToLearn.pdf

Hensley, R. (Director). The medicine wheel [Video/DVD]. First Nations Films/Motions \& Visual Publication. Retrieved from www.motionvisual.com

Hogue, M. (2011). Narratively speaking: Navigating the liminal space of science education between two worlds (Unpublished Doctor of Philosophy dissertation). University of Calgary, Calgary, AB.

Hogue, M. (2012). Inter-connecting Aboriginal and Western paradigms in post-secondary science education: An action research approach. Journal of the Canadian Association of Curriculum Studies, 10 (1), 77-114. Retrieved from http://pi.library.yorku.ca/ojs/index.php/jcacs/article/view/34441

Hogue, M. (2013, Fall). Building bridges: Teaching science through theatre. Education Canada, 53(4), 1-3.

Indian and Northern Affairs Canada (INAC). (2005). Aboriginal post-secondary education and labour market outcomes in Canada 2001. Retrieved from http://www.ainc-inac.gc.ca/pr/ra/pse/01/01_e.pdf

Lewthwaite, B., McMillan, B., Renaud, R., Hainnu, R., \& MacDonald, C. (2010). Combining the views of "both worlds": Science education in Nunavut piqusiit tamainik katisugit. Canadian Journal of Educational Administration and Policy 98, 1-71.Retrieve from: http://www.umanitoba.ca/publications/cjeap/pdf_files/lewthwaiteetal.pdf

Rice, B. (2005). Seeing the world with Aboriginal eyes: A four directional perspective on human and nonhuman values, cultures, and relationships on Turtle Island. Winnipeg, MB: Aboriginal Issues Press. 
Sacks, O. (2002). Uncle Tungsten: Memories of a chemical boyhood. New York, NY: Vintage .

Saskatoon Public Schools. (2004-2008). Instructional strategies online. Retrieved from http://olc.spsd.sk.ca/DE/PD/instr/strats/drill/index.html

Spencer, H. (1966). Herbert Spencer on education. New York, NY: Teachers College Press, Columbia University.

Stamp, N., \& O’Brien, T. (2005). GK-12 partnership: A model to advance change in science education. BioScience-Oxford Journals, 55(1), 70-77.

Statistics Canada. (2005). National tables: Aboriginal data. Retrieved from http://www.statcan.ca.

Statistics Canada. (2008). Aboriginal peoples in Canada in 2006: Inuit, Métis and First Nations (2006 Census. Vol. 8). Ottawa. ON: Government of Canada.

Statistics Canada. (2012). High level indicators: Aboriginal peoples survey 2012. Retrieved from www.statcan.gc.ca.

Stinner, A. (1996). Providing a contextual base and a theoretical structure to guide the teaching of science from early years to senior years. Science \& Education, 5, 247266.

Toscano, M. (2013, March). Is there a crisis in science? Proceedings of the Philosophy of Education Society of Great Britain Annual Conference, New College, Oxford. Retrieve from https://www.philosophy-ofeducation.org/uploads/2013\%20Conference/Papers/Toscano.pdf

Trilling, B., \& Fadel, C. (2009). $21^{\text {st }}$ century skills: Learning for life in our times. San Francisco, CA: John Wiley \& Sons.

Wenger-Nabigon, S. (2010). The Cree medicine wheel as an organizing paradigm of theories of human development. Native Social Work Journal, 7, 139-161. Retrieved from https://zone.biblio.laurentian.ca/dspace/bitstream/10219/387/1/NSWJ-V7-art6p139-161.pdf

\section{Endnotes}

${ }^{1}$ Aboriginal is used interchangeably with First Nations, Métis, and Inuit (FNMI). It is capitalized as a proper noun out of respect for the First Peoples of Canada.

2 Two-eyed seeing is a concept developed by Dr. Cheryl Barlett (professor emeritus) and elders Murdena Marshall and Albert Marshall at Cape Breton University, that has been adopted by many who teach Aboriginal students across the nation (see www.integrativescience.ca). 